\title{
Pancreaticoduodenectomy for the Management of Pancreatic or Duodenal Metastases from Primary Sarcoma
}

\author{
JEREMY R. HUDDY ${ }^{1}$, MIKAEL H. SODERGREN ${ }^{1}$, JEAN DEGUARA ${ }^{1}$, \\ KHIN THWAY ${ }^{2}$, ROBIN L. JONES ${ }^{2}$ and SATVINDER S. MUDAN ${ }^{1,2}$ \\ ${ }^{1}$ Department of Academic Surgery, and ${ }^{2}$ Sarcoma Unit, The Royal Marsden Hospital, London, U.K.
}

\begin{abstract}
Background/Aim: Sarcomas are rare and heterogeneous solid tumours of mesenchymal origin and frequently have an aggressive course. The mainstay of management for localized disease is surgical excision. Following excision there is approximately 30-50\% risk of developing distant metastases. The role of pancreatic resection for metastatic sarcoma is unclear. Therefore, the aim of this study was to asses the outcome of patients with pancreatic metastases of sarcoma treated with surgical resection. Patients and Methods: A retrospective analysis of a prospectively maintained single-surgeon, single-centre database was undertaken. Seven patients were identified who underwent pancreaticoduodenectomy for the management of metastatic disease from sarcoma between 2006-2016. Results: The median age was 59 (range=19-73) years, and there were six females and one male. The primary sites included the uterus, broad ligament, femur and inferior vena cava. One patient died in the early postoperative period. The remaining six patients developed further recurrent disease, with a median disease-free interval of 11 (range=4-27) months and median overall survival of 21 months (range $=4$ days to 86 months). Conclusion: To our knowledge, this is the largest series of patients with pancreatic metastases of sarcoma treated with surgical resection. Despite optimal resection with $R O$ margins, in the absence of effective adjuvant systemic therapies, the benefit of such an approach in metastatic disease remains unclear.
\end{abstract}

Sarcomas are rare tumours with differentiation towards mesenchymal tissue, with an incidence of $1.8-5 / 100,000$ population per year and account for approximately $1 \%$ of all adult cancers (1). The mainstay of treatment for localized

Correspondence to: Mr. Satvinder Mudan, Department of Academic Surgery, The Royal Marsden Hospital, Fulham Road, London SW3 6JJ, U.K. Tel: +44 2073528171, e-mail: satvinder.mudan@rmh.nhs.uk

Key Words: Sarcoma, pancreas, pancreaticoduodenectomy, metastasis. disease is complete surgical excision with or without radiation. The prognosis for patients with retroperitoneal sarcoma is poor, with 5-year survival of between $12 \%$ and $70 \%$ (2), and the main cause of disease-related mortality following surgery is local recurrence (3). However, there is a risk of up to $30 \%$ of developing distant metastases (4), and in these patients, it is the site of metastatic recurrence rather than of the primary sarcoma that determines survival (5). The commonest site for metastases of sarcoma are the lungs.

Metastatic tumours arising in the pancreas are rare, accounting for approximately $2 \%$ of all pancreatic cancer (6, 7). The commonest primary sites for metastasis to the pancreas include cancer from the breast, lung, kidney, skin and colon (8). Resection of metastatic disease within the liver, lung and brain is now common practice in selected metastatic disease, with the strongest evidence reported in the resection of colorectal metastasis, especially liver metastases (9). The morbidity and mortality associated with a pancreatic head resection makes the role of resectional surgery for pancreatic metastases less clearly defined and there are no clinical guidelines. A retrospective study reported improved survival with resection of pancreatic metastases in patients with renal cell carcinoma (7). However, the literature relating to pancreatic metastases of sarcoma is limited to case studies and two small series. A PubMed search retrieved 17 case reports $(6,7-26)$. These included three case series, one consisting of four patients, and the other two reported two patients each. Reddy et al. published a single-institution experience of 49 patients undergoing pancreatic resection for non-pancreatic cancer; this demonstrated resection to be safe and effective in a subgroup of patients, although pathological tumour type influenced survival. Within this series, there were four cases of sarcoma metastases, none of which had evidence histologically of vascular invasion, and postoperatively, the median cumulative survival was 2.6 years (6). Yamamoto et $a l$. describe their experience of two cases and concluded that in selected cases, curative resection can be offered, but as pancreatic metastases are indicative of a more widespread 
multi-visceral recurrence, it is necessary to use aggressive surgical procedures repeatedly to improve prognosis (19). Redmond et al. recently reported two cases of metastatic leiomyosarcoma which underwent pancreaticoduodenectomy, with disease-free intervals of 25 and 15 months and survival of 26 and 17 months (25). Finally, a recent case report and literature review (26) by Robert et al., included 18 patients with pancreatic metastases from leiomyosarcoma. Seven of these patients underwent pancreatic surgery; two subsequently died at 7 and 40 months postoperatively and one developed recurrence at 9 months.

Consequently, the aim of this study was to report the outcome of patients with pancreatic metastases of sarcoma treated with surgical resection at our referral centre, in order to provide a benchmark for further studies and to provide data for clinicians managing metastatic sarcoma.

\section{Patients and Methods}

The Royal Marsden Hospital is a tertiary referral centre for soft-tissue sarcomas. This single-centre, single-surgeon retrospective analysis was performed by interrogation of a prospectively maintained database for the 10-year period 2006 to 2016. During this interval, 6,744 new cases of soft-tissue sarcoma (excluding gastrointestinal stromal tumours) were entered into the database. Seven patients were identified who underwent pancreaticoduodenectomy for the management of sarcoma metastasis involving the pancreas head. During this same period 208 other pancreatic resections for cancer were performed and of these 133 were pancreatoduodenectomies.

Clinical details of initial treatment and subsequent treatment for metastases were collected from a computerised patient medical records system (Electronic Patient Record).

All patients were discussed in a multi-disciplinary team prior to resection of metastatic disease. The diagnosis was confirmed by an experienced soft-tissue pathologist, and histological grade was classified according to the according to the French Federation of Cancer Centres Sarcoma Group (FNCLCC) (27). All seven patients underwent routine surveillance postoperatively with imaging and clinical examination repeated every 3 months. Descriptive statistics were employed.

\section{Results}

Seven patients, one male and six female, underwent pancreaticoduodenectomy for sarcoma metastases. The median age was 59 years (range $=19-73$ years). Two patients had primary retroperitoneal well-differentiated and dedifferentiated liposarcomas. One patient had metastatic osteosarcoma from the femur and the other four all had a histopathological diagnosis of leiomyosarcoma, which ranged from low-to high-grade tumours. Of these, the primary site varied, and included two primary uterine sarcomas, one tumour from the broad ligament, and one that originated in the inferior vena cava. In only one case was the disease pancreas-sparing, affecting only the duodenum (Table I).
One patient had a diagnosis of retroperitoneal liposarcoma with synchronous pancreatic metastases requiring subtotal gastrectomy, pancreaticoduodenectomy, right hemicolectomy, cholecystectomy and excision of two abdominal sarcomatous masses. Six patients had had their primary tumour resected prior to the diagnosis of their pancreatic metastases.

Two patients presented with pancreatico-duodenal metastasis as the first site of disease recurrence. One of these patients had a leiomyosarcoma of the inferior vena cava, and presented with anaemia and abdominal pains after a diseasefree interval (DFI) of 40 months following resection of the primary tumour. She underwent an upper gastrointestinal endoscopy that demonstrated a mucosal tumour in the second part of the duodenum and which on computed tomographic (CT) imaging appeared to be a metastasis within the pancreas eroding into the duodenum. However, postoperative histology demonstrated that the recurrence was limited to the duodenal wall. In the other six patients, metastases originated within the pancreatic parenchyma. The other patient in this group had a dedifferentiated retroperitoneal liposarcoma, and presented with abdominal discomfort, radiating through to the left side of his back after a DFI of 7 years post resection of the primary, which had included an en-bloc resection of the left kidney.

There were four patients who had had a diagnosis of extra-pancreatic sarcoma recurrence prior to the pancreatic metastasis. Three of these patients had leiomyosarcoma histology and one had femoral osteosarcoma. The first patient in this group had high-grade leiomyosarcoma of the broad ligament and developed recurrence in the lung and chest wall 7 months following initial management. The lung deposits responded well to chemotherapy with six cycles of doxorubicin and ifosfamide. Eleven months later, lung metastases were found on surveillance and these were treated with metastectomy of two lung lesions with perioperative gemcitabine and docetaxel to complete remission. Subsequently, there was a 16-month disease-free interval before further metastases in the original abdominal incision. As work-up for further resection a positron emission tomographic (PET) scan showed increased uptake in the region of the duodenum and pancreas. Laparotomy was performed and intra-operatively, this tumour was found to be protruding into the peritoneal cavity but was covered with peritoneum and omentum. Further disease was noted in the retroperitoneum and excised. In addition, a small tumour was felt at the head of the pancreas and a core needle biopsy was undertaken. Histology confirmed metastatic leiomyosarcoma. Four months after this laparotomy, the patient underwent pancreaticoduodenectomy from which she recovered well. However, on postoperative surveillance imaging 7 months following this surgery, she was noted to have progressive disease in the lungs, pelvis and paraspinal region and commenced on gemcitabine and docetaxel. Nineteen months 
Table I. Summary of patients undergoing pancreaticoduodenectomy for management of pancreatic metastases from primary sarcoma.

\begin{tabular}{|c|c|c|c|c|c|c|c|c|c|c|}
\hline Patient & $\begin{array}{l}\text { Age, } \\
\text { years }\end{array}$ & Gender & $\begin{array}{l}\text { Primary } \\
\text { site }\end{array}$ & Histopathology & Grade & $\begin{array}{l}\text { Therapies } \\
\text { preceding pancreatico- } \\
\text { duodenectomy }\end{array}$ & Surgery & $\begin{array}{l}\text { Resection } \\
\text { margin } \\
\text { status }\end{array}$ & $\begin{array}{c}\text { DFI } \\
\text { (months) }\end{array}$ & $\begin{array}{l}\text { Survival } \\
\text { (months) }\end{array}$ \\
\hline 1 & 73 & M & Retroperitoneal & $\begin{array}{c}\text { Liposarcoma } \\
\text { (well-differentiated } \\
\text { and } \\
\text { dedifferentiated) }\end{array}$ & 2 & $\begin{array}{l}\text { Resection of } \\
\text { retroperitoneal } \\
\text { liposarcoma with } \\
\text { left nephrectomy }\end{array}$ & $\begin{array}{l}\text { Laparotomy for } \\
\text { recurrent } \\
\text { retroperitoneal } \\
\text { sarcoma }\end{array}$ & $\mathrm{R} 2$ & $\mathrm{n} / \mathrm{a}$ & (4 days) \\
\hline 2 & 35 & F & $\begin{array}{c}\text { Uterus/broad } \\
\text { ligament }\end{array}$ & Leiomyosarcoma & 3 & $\begin{array}{l}\text { Hysterectomy and BSO } \\
\text { with left pelvic side wal } \\
\text { dissection, resection } \\
\text { retroperitoneal tumour } \\
\text { and partial cystotomy; } \\
\text { radiotherapy, } \\
\text { chemotherapy, } \\
\text { lung metastectomy }\end{array}$ & $\begin{array}{l}\text { Whipple's } \\
\text { procedure }\end{array}$ & R0 & 7 & 47 \\
\hline 3 & 59 & $\mathrm{~F}$ & $\begin{array}{c}\text { Inferior } \\
\text { vena cava }\end{array}$ & Leiomyosarcoma & 2 & $\begin{array}{l}\text { Resection of } \\
\text { leiomyosarcoma } \\
\text { of the inferior } \\
\text { vena cava }\end{array}$ & $\begin{array}{c}\text { Pylorus- } \\
\text { preserving } \\
\text { pancreaticoduo- } \\
\text { denectomy }\end{array}$ & R0 & 27 & 86 \\
\hline 4 & 54 & $\mathrm{~F}$ & Uterus & Leiomyosarcoma & 3 & $\begin{array}{l}\text { Hysterectomy and } \\
\text { BSO, maxilla } \\
\text { resection, } \\
\text { radiotherapy, } \\
\text { laparotomy and } \\
\text { excision pelvic } \\
\text { metastases, left } \\
\text { humerus resection } \\
\text { and reconstruction }\end{array}$ & $\begin{array}{l}\text { Pancreaticoduo- } \\
\text { denectomy }\end{array}$ & R0 & 4 & 21 \\
\hline 5 & 68 & $\mathrm{~F}$ & $\begin{array}{l}\text { Multifocal } \\
\text { abdominal }\end{array}$ & $\begin{array}{c}\text { Liposarcoma } \\
\text { (well-differentiated } \\
\text { and } \\
\text { dedifferentiated) }\end{array}$ & 2 & t & $\begin{array}{l}\text { Laparotomy, sub- } \\
\text { total gastrectomy, } \\
\text { pancreaticoduo- } \\
\text { denectomy, right } \\
\text { hemicolectomy, } \\
\text { cholecystectomy } \\
\text { and excision two } \\
\text { abdominal sarco- } \\
\text { matous lesions }\end{array}$ & $\mathrm{R} 1$ & 11 & 20 \\
\hline 6 & 61 & $\mathrm{~F}$ & Uterus & Leiomyosarcoma & 1 & $\begin{array}{l}\text { Hysterectomy, } \\
\text { right upper } \\
\text { lobectomy, } \\
\text { radiotherapy }\end{array}$ & $\begin{array}{l}\text { Pylorus-preserving } \\
\text { pancreaticoduo- } \\
\text { denectomy and } \\
\text { superior mesenteric } \\
\text { vein resection }\end{array}$ & R0 & 11 & 15 \\
\hline 7 & 19 & $\mathrm{~F}$ & Femur & Osteosarcoma & 2 & $\begin{array}{l}\text { Resection of femur, } \\
\text { pulmonary } \\
\text { metastasectomy }\end{array}$ & $\begin{array}{l}\text { Whipple's } \\
\text { procedure }\end{array}$ & & 20 & 24 \\
\hline
\end{tabular}

M: Male, F: female, DFI: disease-free interval, BSO: bilateral salphingo-oophorectomy, n/a: not available.

following the pancreaticoduodenectomy she presented with small bowel obstruction and underwent laparotomy, limited right hemicolectomy and sigmoid colectomy. The histology of the mesenteric mass causing the obstruction was confirmed to be metastatic leiomyosarcoma. The patient died from progressive disease at 47 months following the pancreatoduodenectomy.
Another patient originally presenting with uterine leiomyosarcoma developed pulmonary metastases 17 years after resection of the primary disease. This was managed with a right upper lobectomy, followed by radiotherapy in view of the involved resection margins on histopathological examination. Two years later, she developed epigastric pain and a PET scan demonstrated recurrence at the head of the 
pancreas. She underwent pylorus-preserving pancreaticoduodenectomy and superior mesenteric vein resection and reconstruction. Histological examination confirmed metastatic leiomyosarcoma. At 11 months following resection, the patient experienced recurrence with a right maxillary mass involving the orbital apex floor and received a further three cycles of docetaxel and gemcitabine. However, she died 15 months postoperatively due to Escherichia coli-associated septicaemia.

The third patient had multiple disease recurrence following her resection of a high-grade leiomyosarcoma of the uterus. She had no adjuvant treatment at the time of the original resection. At 16 months, she developed a maxillary recurrence, with suspicion of a small pulmonary nodule and pelvic lymph node. She underwent surgical macroscopic resection of the maxilla followed by radical radiotherapy. In view of her progressive metastatic disease and the slow growth of her lung nodules, a watch-and-wait strategy was adopted. Her disease progressed 1 month later in the pelvis, prompting a laparotomy and microscopic complete resection. Again, she underwent postoperative radiotherapy but recurrence occurred 5 months on with a pathological fracture of the left humerus. This was managed with surgical excision and reconstruction followed by further radiotherapy to the humerus. Six months later, this patient had emergency presentation with malaena. Upper gastrointestinal endoscopy demonstrated an obstructing lesion in the duodenum that was histologically proven to be metastatic leiomyosarcoma. Imaging by $\mathrm{CT}$ scan demonstrated a $6 \times 7 \mathrm{~cm}$ mass involving the pancreatic head and medial wall of the duodenum wall. There was obstruction of the duodenum lumen and evidence of extrahepatic bile duct dilatation. Of note, the CT scan demonstrated no progression of the lung nodules over 18 months. Following resuscitation and stabilisation, an expedited pancreaticoduodenectomy was undertaken for continued bleeding from the metastasis. Four months following surgery, the patient developed further metastatic disease in the right 4th rib and was given further radiotherapy. One month later chemotherapy was administered for progressive disease in the lungs and pelvis. The patient died 21 months after pancreaticoduodenectomy.

The fourth patient was a 19-year-old female who was initially diagnosed with osteosarcoma of the distal femur. She was treated initially with cisplatin and doxorubicin, which was switched to ifosfamide, etoposide and methotrexate due to cardiotoxicity. She underwent resection of the primary tumour with prosthesis and subsequently enrolled in the 105AD7 osteosarcoma vaccine trial. Fifty-nine months following diagnosis, this patient developed pulmonary metastases, which were originally thought to be unresectable. However, following a partial response to carboplatin and etoposide, she underwent surgical resection of the pulmonary metastases. Sixty-six months following diagnosis, she developed anaemia and was found on imaging to have a $5-\mathrm{cm}$ pancreatic mass invading the duodenum and underwent urgent pancreaticoduodenectomy. The histology confirmed metastatic osteosarcoma in the pancreas. She underwent a further laparotomy 1 month post pancreatoduodenectomy due to adhesional obstruction and was commenced on adjuvant doxorubicin and methotrexate. Unfortunately, she developed metastases in the porta hepatis, liver and peritoneum 20 months postoperatively and died 4 months later.

There was one perioperative mortality giving an overall pancreatoduodenectomy perioperative mortality rate of $1.5 \%$ for the period 2006-2016. This was the only male in the series and the tumour encased the superior mesenteric pedicle. Bleeding was encountered during the dissection around the mesenteric vessels. Difficulty was encountered in securing haemostasis and the abdomen required packing, with a plan for removal after 48 hours. On return to the Intensive Care Unit, the patient had respiratory deterioration, escalating inotrope requirements and died from a massive pulmonary embolus.

All six patients that survived the perioperative period had disease recurrence, with a median DFI of 11 months (range $=4$ 27 months). These patients all had intermediate-high-grade (grade 2-3) tumours. Median overall survival was 21 months (range $=4$ days to 86 months) from pancreatoduodenectomy.

\section{Discussion}

The management of advanced sarcoma remains challenging, with a median overall survival of between 12-18 months from diagnosis of metastatic disease. Chemotherapy forms the mainstay of management of metastatic disease, with an increasing number of systemic therapy options available (28). In addition, other treatment modalities can be used to consolidate treatment, including surgery, radiation, ablation and embolization techniques. The role of immunotherapy in metastatic sarcoma is currently under evaluation, with provisional data indicating single-agent activity of the programmed cell death-1 inhibitor, pembrolizumab, in undifferentiated pleomorphic sarcoma and chondrosarcoma (29). Numerous retrospective studies have been published regarding resection of lung metastases in patients with metastatic sarcoma, however, many of these are limited by small patient numbers, selection bias and limited follow-up. In contrast, there are very few published reports of resection of pancreatico-duodenal metastases in sarcoma, and consequently, the evidence base to guide decision-making is limited.

Advances in surgical oncology and improved systemic therapies have meant that resection of metastatic cancer has now become routine, with a demonstrable survival benefit, most notably in the management of colorectal liver metastases or renal cell carcinoma pancreatic metastases $(9,30)$. Metastatic disease is now detected earlier and more frequently 
due to improvements in imaging quality and protocolised surveillance programs. Despite earlier diagnosis, it is only with the recent decreases in mortality and morbidity associated with pancreatic resection that such surgery is now undertaken. In current practice, high-volume centres report mortality rates of pancreaticoduodenectomy at around $1-3 \%(6,31,32)$ and this is largely because the associated morbidities are better managed and rarely become life-threatening.

However, such operations remain a major undertaking and, as ever, patient selection is critical to identify patients most likely to gain benefit from pancreatic resection. This selection is difficult, especially for those with sarcomas, due to the rarity of the disease and the likelihood of further metastatic disease. Such metastases can occur many years after the resection of the primary sarcoma and are indicative of a more generalised multivisceral process. Therefore, the finding of a metastasis, regardless of location, is indicative of a more generalised shift in the behaviour of that tumour and the natural history thereafter will be dictated by the metastases (with the exception of a symptomatic failure at the primary site, such as a mechanical intestinal obstruction). Furthermore, the significant heterogeneity within sarcoma histological subtypes and the diversity of anatomic locations, makes TNM staging less applicable to clinical practice compared to other tumour groups. However, there is a subgroup of patients that develop complications from metastatic disease, and surgical resection can play an important part in the management of such patients. Criteria for considering surgery include disease confined to the operative field and a reasonable DFI following prior treatment.

Our study is the largest series to date of the surgical management of sarcoma patients with pancreatic metastases and yet the series has only seven patients. This is further confounded by the heterogeneity of sarcoma, with included patients having a biologically diverse range of primary diseases. It is unlikely that outside of a large multi-centre international study that we could achieve substantially larger numbers. We can conclude that following resection of metastatic sarcoma in the pancreas, it is likely that further recurrent disease will develop. However, two of our patients presented with abdominal pain and more than half with anaemia. Consequently, surgery could be offered to patients with symptoms and localized metastatic disease. It is important that such patients are managed within the context of experienced sarcoma and hepatobiliary multidisciplinary teams.

Yamamoto et al. in their interpretation of the role of surgery in this patient group suggest that if radical, potentially curative resection is to be offered, then it should be in the knowledge that further aggressive resectional surgery may be required. The utility of repeated resection of metastatic disease (within the context of multi-disciplinary management) can be seen in that four of our patients underwent multiple resections before their pancreatic resection, with patients undergoing between one to three resections in addition to resection of their primary tumour before pancreaticoduodenectomy.

The benefit of surgical resection remains unclear, and all patients in our series developed further recurrent disease. However, this approach may play a role in those with symptoms. In addition, this study provides a valuable benchmark for future studies and guidance to physicians managing metastatic sarcoma. It is very unlikely that a randomised controlled trial of resection of metastatic sarcoma will ever be performed and evidence for any benefit of surgery would require a large international registry and quality of life data.

\section{Disclosures}

The Authors have no conflicts of interest to disclose.

\section{Acknowledgements}

The Authors acknowledge support from the NIHR Royal Marsden/ICR Biomedical Research Centre.

\section{References}

1 Wibmer C, Leithner A, Zielonke N, Sperl M and Windhager R: Increasing incidence rates of soft tissue sarcomas? A populationbased epidemiologic study and literature review. Ann Oncol 21: 1106-1111, 2010.

2 Piyaresh A, Chee Y, Helliwell TR, Hershman MJ, Leinster SJ, Fordham MV and Poston GJ: The management of retroperitoneal soft-tissue sarcoma: a single institution experience with a review of the literature. Eur J Surg Onc 27(5): 491-497, 2001.

3 Strauss DC, Hayes AJ, Thway K, Moskovic EC, Fisher C and Thomas JM: Surgical management of primary retroperitoneal sarcomas. Br J Surg 97(5): 698-706, 2010.

4 Mendenhall WM, Zlotecki RA, Hochwald SN, Hemming AW, Grobmyer SR and Cance WG: Retroperitoneal soft-tissue sarcoma. Cancer 104(4): 669-675, 2005.

5 Potter DA, Glenn J, Kinsella T, Glatstein E, Lack EE, Restrepo C, White DE, Seipp CA, Wesley R and Rosenberg SA: Patterns of recurrence in patients with high-grade soft-tissue sarcomas. J Clin Oncol 3(3): 353-366, 1985.

6 Reddy S, Edil BH, Cameron JL, Pawlik MPH, Hermann JM, Gilson MM, Campbell KA, Schulick RD, Ahuja N and Wolfgang CL: Pancreatic resection of isolated metastases from nonpancreatic primary cancers. Ann Surg Oncol 15(11): 31993206, 2008.

7 Sperti C, Moletta L and Pantanè G: Metastatic tumors to the pancreas: The role of surgery. World J Gastrointest Oncol 6(10): 381-392, 2014.

8 Sperti C, Pasquali C, Liesssi G, Pinciroli L, Decet G and Pedrazzoli S: Pancreatic resection for metastatic tumour to the pancreas. J Surg Onc 83: 161-6, 2003.

9 Primrose JN: Surgery for colorectal liver metastases. Br J Cancer 102: 1313-1018, 2010. 
10 Nobili C, Lesevic V, Marzano E, Casnedi S, Greget M, Bachellier P and Pessaux P: Primary pancreatic sarcoma with liver metastases: Is there a place for radical surgery? Gastroenterol Clin Biol 34(3): 227-230, 2010.

11 Reddy $\mathrm{S}$ and Wolfgang CL: The role of surgery in the management of isolated metastases to the pancreas. Lancet Oncol 10(3): 287-293, 2009.

12 Koh YS, Chul J, Cho CK and Kim HJ: Pancreatic metastasis of leiomyosarcoma in the right thigh: a case report. World $\mathrm{J}$ Gastroenterol 13(7): 1135-1137, 2007.

13 Iwamoto I, Fujino T, Higashi Y, Tsuji T, Nakamura N, Komakata $\mathrm{T}$ and Douchi T: Metastasis of uterine leiomyosarcoma to the pancreas. J Obstet Gynaecol Res 31(6): 531-4, 2005.

14 Jarufe N, McMaster P, Mayer AD, Mirza DF, Buckels JA, Orug T, Tekin K and Bramhall SR: Surgical treatment of metastases to the pancreas. Surgeon 3(2): 79-83, 2005.

15 Kurtz JE, Andrès E, Rohr S, Maloisel F, Mechine A, Meyer C and Dufour P: Pancreatic metastasis of alveolar soft-part sarcoma: A case report and review of the literature. Ann Oncol 12(6): 865-867, 2001.

16 Piscitelli D, Sanguedolce F, Mattioli E, Parisi G, Fiore MG and Resta L: Unusual presentation of metastatic osteosarcoma as a giant duodenal polyp. A case report. Pathologica 97(2): 88-91, 2005.

17 Fotiadis C, Charalambopoulos A, Chatzikokolis S, Zografos GC, Genetzakis $M$ and Tringidou R: Estraskeletal myxoid chrondrosarcoma metastatic to the pancreas: a case report. World J Gastroenterol 11(14): 2203-2205, 2005.

18 Yokoyama Y, Murakami Y, Sasaki M, Morifuji M, Hayashidani Y, Kobayashi T, Sudo T and Sueda T: Pancreatic metastasis of dermatofibrosarcoma protuberans. J Gastroenterol 39(8): 798800,2004

19 Yamamoto H, Watanabe K, Nagata M, Honda I, Watanbe S, Soda $\mathrm{H}$ and Tatezaki S: Surgical treatment for pancreatic metastasis from soft-tissue sarcoma: report of two cases. Am J Clin Oncol 24(2): 198-200, 2001.

20 Ishigure K, Kaneko T, Takeda S, Inoue S, Kawase Y and Nakao A: Pancreatic metastasis from leimyosarcoma of the back. Hepatogastroenterology 50(53): 1675-1677, 2003.

21 Medina-Franco $\mathrm{H}$, Halpern NB and Aldrete JS: Pancreaticoduodenectomy for metastatic tumors to the periampullary region. J Gastrointest Surg 3(2): 119-122, 1999.

22 Burke JP, Maguire D, Dillon J, Moriarty M, O'Toole GC: Whipple's procedure for an oligometastasis to the pancreas from a leiomyosarcoma of the thigh. Ir J Med Sci 181(3): 361-363, 2012.

23 Hernández S, Martín-Fernández J, Lasa I, Busteros I and GarcíaMoreno F: Pancreaticoduodenectomy for metastasis of uterine leiomyosarcoma to the pancreas. Clin Transl Oncol 12(9): 643645,2010 .
24 Lasithiotakis K, Petrakis I, Georgiadis G, Paraskakis S, Chalkiadakis $G$ and Chrysos E: Pancreatic resection for metastasis to the pancreas from colon and lung cancer, and osteosarcoma. JOP 11(6): 593-596, 2010.

25 Redmond CE, Adler H, Heneghan HM, Kelly R, Swan N, Cantwell CP, Maguire D, Traynor O, Hoti E, Geoghegan JG and Conlon KC: Pancreatic metastasectomy: experience of the Irish National Surgical Centre for Pancreatic Cancer. Ir J Med Sci 183(4): 677-80, 2014.

26 Robert PE, Orry D, Mor C, Rosset, P, Guyetant S, Salame E, de Calan L: Resectable pancreatic metastasis of left thighbone leiomyosarcoma: Case report and literature review. J Gastrointest Canc 43: 40-43, 2012.

27 Guillou L, Coindre JM, Bonichon F, Nguyen BB, Terrier P, Collin F, Vilain MO, Mandard AM, Le Doussal V, Leroux A, Jacquemier J, Duplay H, Sastre-Garau X, Costa J: Comparative study of the National Cancer Institute and French Federation of Cancer Centres Sarcoma Group grading systems in a population of 410 adult patients with soft-tissue sarcoma. J Clin Oncol 15: 350-362, 1997.

28 Noujaim J, Thway K, Sheri A, Keller C and Jones RL: Histology-driven therapy: the importance of diagnostic accuracy in guiding systemic therapy of soft tissue tumors. Int J Surg Pathol 24(1): 5-15, 2016.

29 Tawbi HA, Burgess MA, Crowley J, Van Tine BA, Hu J, Schuetze S, D'Angelo SP, Attia S, Priebat DA, Okuno SH, Riedel RF, Davis LE, Movva S, Reed DR, Baker LH, Reinke DK, Maki RG and Patel S: Safety and efficacy of PD-1 blockade using pembrolizumab in patients with advanced soft tissue (STS) and bone sarcomas (BS): Results of SARC028 - A multicenter phase II study. ASCO Annual Meeting Abstract 11006 (JCO 34), 2016.

30 Strobel O, Hackert T, Hartwig W, Bergmann F, Hinz U, Wente MN, Fritz S, Schneider L, Büchler MW and Werner J: Survival data justifies resection for pancreatic metastases. Ann Surg Onc 16(12): 3340-3349, 2009.

31 Cameron JL, Taylor S, Coleman J and Belcher KA: One thousand consecutive pancreaticoduodenectomies. Ann Surg 244(1): 10-15, 2006.

32 Michalski CW, Weitz J and Buchler MW: Surgery insight: Surgical management of pancreatic cancer. NCPO 4: 526-535, 2007. 